\title{
Little Dutch boy
}

\section{A delicate balancing act.}

\begin{abstract}
Jeff Crook
My youngest son was always a precocious yet angry child. He was accepted at the Copenhagen Science Academy at the age of 9 and achieved his doctorate in dimensional physics at 12 . He was never happy in school, and should have graduated much sooner, but they held him back as long as was safe, considering his political connections. After all, it was his antigravity platform that saved Copenhagen from the encroaching sea.
\end{abstract}

After graduation, he wasn't allowed to work, thanks to the child labour laws of the time, so he found himself with many an empty hour to idle away in the house we gave him, tinkering with his instruments. Like any other boy, he was especially fond of his lasers and particle accelerators. My wife and I chose to live under a tent atop a raised platform outside the blast radius, which he had graciously drawn on a map for us, because he still had room in his calculating little heart for his mummy.

One day, out of the blue, I found him crying like a child. He was afraid, he said, and when I asked why, he said he feared Earth was well on its way to becoming a second Venus.

When I asked him what

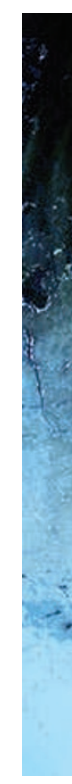

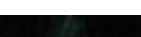

Perhaps it was the frost clinging to his hair.

"It's only cut off, a clean cut, cauterized." I stooped beside him to examine it. "You can still move." The air was bitterly cold. The clouds that condensed around my words began to spin, becoming a misty vortex that spiralled down to the stump of his dismembered finger and vanished as if down a drain.

"I've made a serious error in my calculations," he chattered, frigidly.

"Nonsense. You've never made an error before." He was taller, his hair longer, and he had begun to grow a beard, though he was only 14 .

He said: "It's all about the spinning of he meant, he asked. "Wha has happened to the heat of Uranus?" as if he had misplaced it himself. "One a hot planet, much hotter than it should be; the other cold, much colder than it should be." He wandered his empty house like the ghost of Sherlock Holmes, puffing on the problem. He was determined to solve the mystery, much as he had once solved Metgarth's equation.

On the final day of his life, I received a distressed and broken call from him. I hurried to the house, where I found him in the basement amid his contraptions, painfully gripping his wrist, rooted to the spot beside the particle accelerator we had purchased for his birthday. "It hurts!" he cried.

Moving closer, I saw that he had lopped off the index finger of his right hand just above the second knuckle. Strangely, there was no blood. He looked different from the last time I had seen him, older somehow. large bodies in space. I read about it in an old book of alchemy written by Sir Isaac Newton. Never published, because in it he repudiated all his previous theories, but I found a copy in Dr Leonardo's safe."

"You broke into his safe?"

"Newton predicted that Venus would be abnormally hot and dry because of its angular momentum. His theories predict that a planet with Uranus's angular momentum would have no interior heat at all. A spinning mass in space draws energy from other dimensions ..."

"Son, that's astrology," I said. I knew, because I was an astrologer. You might suggest that I should have seen this coming, but I didn't. He was a Libra. I never expected him to upset the balance.

He waved his free hand impatiently. $\mathrm{He}$ was now older than me, his face gaunt he looked like my grandfather. "Angular

momentum regulates the flow of energy between dimensions. Earth's current angular momentum, relative to the other stars and planets, has resulted in a net increase in energy. So I built a dimensional laser. You see it there," he said, nodding at an intricate astrolabe made of crystal and platinum. It was a beautiful thing, a work of art, completely unlike the bulky, shrieking toys of his childhood. It was plugged into a potbellied stove, glowing red with heat, beneath the stairs.

"You invented a working fusion reactor," I said proudly. Despite his long white beard, he was still my son.

"I used it to punch a photon-sized hole into another universe. Our excess energy should have drained into it, stabilizing the planetary temperatures. I was off by no more than a tenth of a degree, but I hit a universe of absolute zero, in which the Big Bang has not yet taken place. Possibly this will be its trigger. Meanwhile, our space-time ripped apart, the hole widened ..."

"And you plugged it with your finger," I said to my dear, foolish boy.

"It was the only way to stop it.”

"But for how long?"

His hand was frozen solid, ice was creeping up his sleeve, and he was far older than I would ever live to be. "Go," he said to me in his quaver-
ing, reedy voice. But I couldn't, not until the end.

The changes here have wrought changes in the stars - astrology in retrograde. The loss of energy on this world has altered the angular momentum of the other planets. The temperature today hit 30 below, but they say we can all move to Venus before the magnetosphere collapses completely. Oceans are forming again on Mars, and though it's much colder there, Venus is too much like the Earth of my memory, when my boy was still a child.

Jeff Crook is alive and confined to a single universe. Current coordinates: North Mississippi, United States of America, early twenty-first century. Sharing crew quarters with one mate, two offspring and a pair of small decorative mammals. 